\title{
Adipocytes promote cholangiocarcinoma metastasis through fatty acid binding protein 4
}

Jihua Nie ${ }^{1,2,3+}$, Jingying Zhang ${ }^{1+}$, Lili Wang ${ }^{4 \dagger}$, Lunjie Lu', Qian Yuan ${ }^{1}$, Fangmei An $^{5}$, Shuyu Zhang ${ }^{1,2^{*}}$ and Yang Jiao ${ }^{1,2^{*}}$

\begin{abstract}
Background: The early occurrence regional nodal and distant metastases cholangiocarcinoma (CCA) is one of the major reasons for its poor prognosis. However, the related mechanisms are largely elusive. Recently, increasing evidences indicate that adipocytes might be involved in the proliferation, homing, migration and invasion of several malignancies. In the present study, we attempt to determine the effects and possible mechanisms of adipocytes on regulating progression of CCA.

Methods: Adipocyte-CCA cell co-culture system and CCA metastasis mice model were used to determine the effects of adipocytes on CCA metastasis. We identified the biological functions and possible mechanisms of adipocyte-derived fatty acid binding protein 4 (FABP4) in regulating the adipocyte-induced CCA metastasis and epithelial-mesenchymal transition (EMT) phenotypes, both in vitro and in vivo.

Results: Adipocyte-CCA cell co-culture promotes the in vitro and in vivo tumor metastasis, leading to increased adipocyte-derived fatty acid absorbance and intracellular lipids of CCA cells, which indicates adipocytes might function as the energy source for CCA progression by providing free fatty acids. Further, highly expressed FABP4 protein was identified in adipose tissues and fully differentiated adipocytes, and upregulated FABP4 was also detected by qRT-PCR assay in CCA cells co-cultivated with adipose extracts as compared to parental CCA cells. The specific FABP4 inhibitor BMS309403 significantly impaired adipocyte-induced CCA metastasis and EMT phenotypes both in vitro and in vivo.

Conclusions: Together, the results demonstrate that the adipocyte-CCA interaction and the energy extraction of CCA cells from adipocytes are crucial for the invasion, migration and EMT of CCA cells. FABP4 from adipocytes mediates these adipocyte-induced variations in CCA cells, which could serve as a potential target for the treatment of CCA.
\end{abstract}

Keywords: Cholangiocarcinoma, Metastasis, Adipocytes, Fatty acid-binding protein 4 (FABP4), Epithelial-mesenchymal transition (EMT)

\section{Background}

Cholangiocarcinoma (CCA), which can be categorized into perihilar, distal and intrahepatic CCA, originates from epithelial cells located within the biliary tree [1]. In the United States, the cumulated mortality rate of CCA has increased by 39\% [2]. In Asia and South America, the incidence rate of CCA is 96 cases per 100,000, which

\footnotetext{
* Correspondence: zhang.shuyu@hotmail.com; jiaoyang@suda.eud.cn ${ }^{\dagger}$ Equal contributors

${ }^{1}$ Department of Radiation Genetics, School of Radiation Medicine and Protection, Medical College of Soochow University, Suzhou 215123, China Full list of author information is available at the end of the article
}

is even higher than that of US [3]. The significantly increased incidence, high mortality rate and poor prognosis of CCA have attracted increasing research interest in recent years [1, 4]. Unfortunately, due to the early occurrence regional nodal and distant metastases, only $10 \%$ of CCA patients are surgically resectable and curable, which leads to the poor prognosis with a median survival of less than one year $[1,5]$.

The profound genetic heterogeneity, highly desmoplastic nature and rich tumor microenvironment of CCA are thought to account for its early and extensive onset of metastasis $[1,6,7]$. For example, Yoshikawa et al. reported 
that the epidermal growth factor receptor overexpression was associated with lymph node metastasis, lymphatic vessel invasion and perineural invasion in extrahepatic CCA, and vascular endothelial growth factor overexpression with intrahepatic metastasis in intrahepatic CCA [8]. In addition, several studies have indicated that epigenetic modifications of genes involved in progression turned out to be another possible mechanism underlying CCA metastasis [9]. For instance, E-cadherin promoter methylation was found to be associated with increased migration and invasion in CCA [9-14]. Nonetheless, the mechanisms related to CCA metastases remain incompletely understood.

CCA is located near the omentum and mesentery, therefore surrounded by a rich tumor microenvironment composed of heterogeneous stromal cells including adipocytes [15]. Adipocytes are one of the key components of the supportive microenvironment for nearby tumor cells, which functions to serve as an energy source by releasing free fatty acids (FAs), as well as to derive a wide variety of adipokines and signaling factors involved in tumor formation and progression [15-19]. Recently, adipocytes have been regarded to be involved in regulating matrix remodeling, invasion, and epithelialmesenchymal transition (EMT), which is a pivotal mechanism for tumor metastatic dissemination [7, 20, 21], in several human cancers [22, 23]. For example, Nieman et al. demonstrated that adipocyte-derived FAs and soluble factors promoted the homing, migration and invasion of ovarian cancer cells in 2011 [18]. Also, enhanced lipolysis and increased $\beta$-oxidation were respectively observed in adipocytes and co-cultured ovarian cancer cells. Afterwards, growing evidences showed that adipocytes promoted proliferation and progression of several malignancies such as colon, breast, and renal cancers etc. [24-28].

Although the association between obesity and CCA has been reported in a meta-analysis in 2014 [29], the association between adipocytes and CCA progression remains unknown, not to mention the underlying mechanisms. To identify the association between adipocytes and CCA metastasis, the present study demonstrated, for the first instance, the effects of adipocytes on CCA metastasis and the related mechanism, which may reveal a potential therapeutic target against CCA progression.

\section{Methods}

\section{Adipose tissues and preparation of extracts}

Human adipose tissues from the breast cancer patients ( $>2 \mathrm{~cm}$ away from tumors) and the omentum majus adipose from the nontumorous patients were provided by the First Affiliated Hospital of Soochow University less than $1 \mathrm{~h}$ after surgery. This study was approved by the Institutional Review Board of Soochow University.
Under aseptic conditions, the adipose tissues were washed with icy-cold PBS containing $50 \mu \mathrm{g} / \mathrm{ml}$ gentamicin, cut into small pieces with a diameter of $2 \mathrm{~mm}$, and then centrifuged briefly to remove red blood cells and debris. Adipose tissues then were incubated in DMEM culture medium ( $80 \mathrm{mg}$ adipose/mL DMEM medium) for $24 \mathrm{~h}$ at $37^{\circ} \mathrm{C}$ under $5 \% \mathrm{CO}_{2}$. Adipose tissue extracts were obtained by removing lipochondrions via $0.45 \mu \mathrm{M}$ filter filtration (EMD Millipore, Billerica, MA, USA). After incubation with the extracts for $24 \mathrm{~h}$, the cancer cells were harvested for subsequent experiments.

\section{Pre-adipocyte differentiation induction assay}

A differentiation assay was performed as previously described [30]. Briefly, 3 T3-L1 cells were first incubated in differentiation media I consisting of DMEM, $10 \%$ fetal bovine serum (FBS), $0.25 \mu \mathrm{g} / \mathrm{mL}$ insulin, $1 \mu \mathrm{M}$ dexamethasone, and $0.5 \mathrm{mM}$ 3-isobutyl-1-methylxanthine (SigmaAldrich, St. Louis, MO, USA). Two days later, the cells were cultured in complete culture medium and $0.25 \mu \mathrm{g} /$ $\mathrm{mL}$ insulin (differentiation media II) until lipid droplets formed. Oil Red O staining (Abcam, Cambridge, MA, USA) was employed to determine differentiation status as previously described [30]. The supernatant was collected prior to lipid droplet staining through centrifugation; the supernatant was used in subsequent experiments.

\section{Cell culture, drug treatment and adenovirus infection}

The human CCA cell lines RBE and Hccc-9810 were maintained in RPMI 1640 containing 10\% FBS, Lglutamine $(2 \mathrm{mM})$, non-essential amino acids $(2 \mathrm{mM})$, penicillin $(100 \mathrm{U} / \mathrm{mL})$, and streptomycin $(100 \mathrm{U} / \mathrm{mL})$ (Gibco, Grand Island, NY, USA) at $37{ }^{\circ} \mathrm{C}$ under $5 \% \mathrm{CO}_{2}$ atmosphere. BMS309403 (Sigma-Aldrich, St. Louis, MO, USA) was dissolved in DMSO (Sigma-Aldrich, St. Louis, $\mathrm{MO}, \mathrm{USA}$ ) at $20 \mathrm{mM}$ to prepare a stock solution. In the subsequent studies, $20 \mu \mathrm{M}$ BMS309403 was used as working solution.

Full-length cDNA of an adenovirus-carrying human FABP4 was constructed for in vivo expression of FABP4 (ViGene, Shandong, China). Sub-confluent cells were mock-infected or infected with adenovirus in complete medium for $12 \mathrm{~h}$ at $37{ }^{\circ} \mathrm{C}$ followed by incubation in fresh complete medium for additional $24 \mathrm{~h}$ to $48 \mathrm{~h}$ for subsequent experiments. The infection efficiency was confirmed by detection of FABP4 mRNA by quantitative real-time PCR (qRT-PCR).

\section{Wound healing migration assay}

$3 \times 10^{5} / \mathrm{mL}$ exponentially grown CCA cells were split and seeded into 6-well tissue culture plates and allowed to form a confluent monolayer. After a corresponding treatment, the monolayer was scratched with the tips of $200 \mu \mathrm{L}$ sterile pipettes, washed with PBS to remove 
floating and detached cells, and cultured with fresh medium supplemented with $2 \%$ FBS. To assess cell migration, we designated five randomly chosen points for each treatment group for photographing at 0, 12, 24, and $48 \mathrm{~h}$ by using a microscope (40x, Olympus, Tokyo, Japan) equipped with a digital camera (Canon, Tokyo, Japan); the images were analyzed using Image J software (National Institutes of Health, Bethesda, MD, USA). Cell migration was presented as means \pm sd of wound width, and the values were compared with those at the starting time point in the control group.

\section{Transwell invasion assay}

The invasion assay was performed using 24-well Matrigel Invasion Chambers (pore size, $8 \mu \mathrm{m}$; Corning, Tewksbury, MA, USA). Inserts were pre-coated with $50 \mu \mathrm{L}$ of Matrigel (1:8 dilution; BD Biosciences, San Jose, CA, USA) and then polymerized at $37^{\circ} \mathrm{C}$ for $4 \mathrm{~h}$ before the experiment. $5 \times 10^{4} / 100 \mu \mathrm{L}$ CCA cells were prepared as a single cell suspension in serum-free medium containing $0.2 \%$ bovine serum albumin (BSA) and seeded onto the upper chambers. The lower chamber was filled with complete culture medium supplemented with/without adipose tissue extracts or filled with culture supernatant from differentiated 3 T3-L1 cells. After incubation for $24 \mathrm{~h}$, the cells on the surface of the upper chambers were scraped off. The invading cells were fixed with $4 \%$ paraformaldehyde, stained with Giemsa staining solution at room temperature for at least $4 \mathrm{~h}$, and photographed under a microscope.

\section{Free FA assay}

Cells were plated into a 24-well plate and treated accordingly. The medium was collected and centrifuged at $10,000 \mathrm{~g}$ for $5 \mathrm{~min}$ at $4{ }^{\circ} \mathrm{C}$ prior to determination. Nonesterified FA (NEFA) in the culture media was analyzed using colorimetric assays according to the manufacturer's instructions (Labassay NEFA Kit, Wako, Osaka, Japan).

\section{Immunofluorescence staining}

Cells were grown on $35 \mathrm{~mm}$ glass bottom culture dishes (Nest Scientific, NJ, USA). After the corresponding treatments, the cells were washed with PBS and fixed with $4 \%$ paraformaldehyde, stained with $20 \mu \mathrm{g} / \mathrm{mL}$ Bodipy 493/503 (ThermoFisher Scientific, Grand Island, NY, USA) for $1 \mathrm{~h}$ at room temperature, and washed twice with PBS. The nuclei were visualized using Hoechst $33342(0.5 \mu \mathrm{g} / \mathrm{mL})$, and the stained cells were observed under a confocal scanning laser microscope (Olympus, Tokyo, Japan). The relative fluorescence intensity was analyzed using Image J software.

\section{Western blot assay}

Cells were harvested and lysed in $50 \mathrm{uL}$ of lysis buffer containing protease inhibitor cocktail (Roche Life Science, Indianapolis, IN, USA) for $30 \mathrm{~min}$ on ice. Total protein $(50 \mu \mathrm{g})$ from each lysate was fractionated by $10 \%$ SDSPAGE and transferred onto polyvinylidene fluoride microporous membranes. After blocking with $5 \%$ nonfat milk in PBS-Tween-20 for $2 \mathrm{~h}$ at room temperature, the membranes were incubated with primary antibody overnight at $4{ }^{\circ} \mathrm{C}$ and then incubated with corresponding secondary antibodies. GAPDH was used as loading control.

The primary antibodies used were rabbit anti-FABP4 (EPR3579, Abcam, Cambridge, MA, USA, 1:1000), rabbit anti-claudin 1 (Abcam, Cambridge, MA, USA, 1:1000), rabbit anti-occludin (EPR8208, Abcam, Cambridge, MA, USA, 1:50,000), rabbit anti-E-cadherin (EP700Y, Abcam, Cambridge, MA, USA, 1:10,000), rabbit anti-SNAIL (Abcam, Cambridge, MA, USA, 1:1000), rabbit antiSmad3 (EP568Y, Abcam, Cambridge, MA, USA, 1:1000), rabbit anti- $\beta$-catenin (Cell Signaling Technology, Danvers, MA, USA, 1:1000), rabbit anti-MMP2 (Cell Signaling Technology, Danvers, MA, USA,1:1000), rabbit anti-MMP9 (Cell Signaling Technology, Danvers, MA, USA,1:1000), and anti- $\beta$-actin (Beyotime Biotechnology, Haimen, China). The secondary antibodies used were goat anti-mouse and anti-rabbit horseradish peroxidaseconjugated antibodies (1:1000, Beyotime Biotechnology, Haimen, China). Protein expression was quantified using Image J software.

\section{qRT-PCR assay}

Total RNA from each group of RBE cells was extracted using TRIzol (Invitrogen, Grand Island, NY, USA) according to the standard TRIZOL method. First-strand cDNA was synthesized from $1 \mu \mathrm{g}$ of RNA per sample by using Transcriptor First Strand cDNA Synthesis Kit (Roche Life Science, Indianapolis, IN, USA). Real-time PCR was performed on an Applied Biosystems ViiA 7 RT-PCR by using SYBR Green (Thermofisher Scientific, Grand Island, NY, USA). Table 1 shows the primers for

\begin{tabular}{|c|c|c|}
\hline Gene & $\begin{array}{l}\text { Forward primer sequence } \\
\left(5^{\prime}-3^{\prime}\right)\end{array}$ & $\begin{array}{l}\text { Reverse primer sequence } \\
\left(5^{\prime}-3^{\prime}\right)\end{array}$ \\
\hline FABP1 & AGTGGTTCAGTTGGAAGGTGA & GCAGACTTGTTAAATTCTCTTGC \\
\hline FABP2 & ATTTCCATTCATGCCAAAG & TCCACTACATTCCAGCCTGA \\
\hline FABP3 & ACACTTGTGCGGGAGCTAAT & CATGGGAACTGGAACTGGAT \\
\hline FABP4 & ACCTTAGATGGGGGTGTCCT & ACGCATTCCACCACCAGTTT \\
\hline FABP5 & ACAGATGGTGCATTGGTTCA & CCTGTCCAAAGTGATGATGG \\
\hline FABP6 & CTCAGAGATCGTGGGTGACA & CGAGCAGCGTCTGTCCTTAT \\
\hline FABP7 & ACAGAAATGGGATGGCAAAG & ATTाTCCACCTCCACACCAA \\
\hline GAPDH & CAGGAGGCATTGCTGATGAT & GAAGGCTGGGGCTCATTT \\
\hline
\end{tabular}


FABP1-7 and the internal control GAPDH. Gene expression was calculated using the $2^{-\triangle \Delta C T}$ method.

\section{In vivo analysis of CCA metastasis in nude mice}

Five-week-old female outbred nude mice were purchased from Shanghai SLAC Laboratory Animal Co., Ltd. (Shanghai, China) and housed in a pathogen-free facility with constant temperature and humidity control. CCA metastasis mouse models were constructed by injecting $1 \times 10^{6} / 100 \mu \mathrm{L}$ RBE cells through the tail vein. Briefly, the mice were randomly divided into five groups, which were separately injected with (1) parental RBE cells, (2) RBE cells co-cultured with human omentum adipose for $24 \mathrm{~h}$, (3) RBE co-cultivated with human adipose and FABP4 inhibitor BMS309403 for $24 \mathrm{~h}$, and (4 and 5) RBE cells infected with control adenovirus and FABP4 adenovirus for $24 \mathrm{~h}$, respectively. For short-term imaging assay, all cells were infected with green fluorescent protein (GFP)-tagged adenovirus for additional $24 \mathrm{~h}$, collected and washed twice with cold PBS, and then resuspended in cold PBS. 24 h after injection, colonization of RBE cells in organs of nude mice was visualized using an in vivo imaging system (Kodak, Effingham, IL, USA). All photos were taken under the same condition. The relative fluorescence intensity of the tissues was calculated using Image J analysis software. For long-term observation of metastasis, all mice were euthanized 1 month after injection through the tail vein, and their livers and lungs were extirpated and used in pathological examination as described below. The design and implementation of this study were approved by the Ethics Committee of Soochow University.

\section{Histopathological and immunohistochemistry assay}

All of the animals were euthanized 1 month after injection through the tail vein. The liver, heart, kidney, and lung of each mouse were excised. Tissues were fixed in 10\% neutralbuffered formalin and embedded in paraffin for $\mathrm{H}$ \& $\mathrm{E}$ staining and immunohistochemistry as previously described [31] to determine the metastasis of RBE cells in vivo.

For immunohistochemistry, $4 \mu \mathrm{m}$ paraffin sections were deparaffinized and heat-treated with citrate buffer ( $\mathrm{pH}$ 6.0) for $3 \mathrm{~min}$ according to an antigen retrieval protocol. Non-specific binding sites were subsequently blocked with $5 \%$ BSA for $30 \mathrm{~min}$. The sections were incubated overnight with primary antibodies (1:200 dilution) at $4{ }^{\circ} \mathrm{C}$. Subsequently, the sections were incubated with secondary antibody dilution (Zhongshan Golden Bridge Biotechnology, Beijing, China) at $37{ }^{\circ} \mathrm{C}$ for $1 \mathrm{~h}$ followed by diaminobenzidine (DAB) substrate detection, washing, hematoxylin staining, dehydration and mounting. Images of the tissue sections were captured using an Olympus optical microscope (Tokyo, Japan).
For Oil Red O staining, $10 \mu \mathrm{m}$ frozen sections made from fresh frozen tissues were air-dried at room temperature, incubated in fresh Oil Red O (Abcam, Cambridge, MA, USA) for $10 \mathrm{~min}$, and rinsed in water. Images of the slides were viewed and captured under an Olympus optical microscope (Tokyo, Japan).

\section{Statistics}

All experiments were performed in triplicate and data were expressed as mean \pm sd. SPSS Statistics (Version 19.0, IBM, Armonk, NY, USA) was used for student's ttest or one-way ANOVA to evaluate differences. $P<0.05$ indicates significant difference.

\section{Results}

Adipose tissue extracts enhance CCA invasion and migration in vitro

Tumor microenvironment, which consists of tumorassociated extracellular matrix and stromal cells, is important for tumor growth and progression [32]. To determine the effects of adipose tissues, a major component of tumor microenvironment, on CCA invasion and migration, we incubated the human CCA cell line RBE with extracts of adipose tissues obtained from different species or origins. Figure 1a showed that the invasion of RBE cells, cultured in the presence of the four human adipose tissue extracts, was significantly increased compared with those of the control group $(P<0.05)$, indicating that the acquired invasiveness of CCA cells was due to cultivation with adipose tissue extracts. Moreover, enhanced migration of RBE cells cultured with adipose tissue extracts was also detected by wound healing assay (Fig. 1b), in which the enhanced migration was indicated by obvious shrinking of "wound" width $24 \mathrm{~h}$ following scratching compared with that in the control group $(\mathrm{P}<$ $0.05)$. Enhanced invasion and migration were also observed in RBE cells grown in extracts of adipose tissue from C57/BL6J omentum (Fig. 1c and d).

Adipose tissues consist mainly of mature adipocytes, which play potential roles in ovarian cancer and breast cancer progression $[18,32]$. In the present study, mouse pre-adipocyte 3 T3-L1, which can differentiate into mature adipocytes [30], was utilized to determine the effects of adipocytes on RBE metastasis in vitro. As shown in Fig. 1e, pre-adipocyte 3 T3-L1 could be induced to differentiate into mature adipocytes, characterized by the presence of typical lipid droplets in the cytoplasm [30]. Compared with RBE cells grown in complete growth medium, RBE cells co-cultured with undifferentiated 3 T3-L1 exhibited a stronger invasive tendency $(P<0.05)$. Moreover, cocultivation with fully differentiated 3 T3-L1 cells significantly increased the number of trans-membrane cells, in contrast to pre-adipocyte-co-cultured RBE 


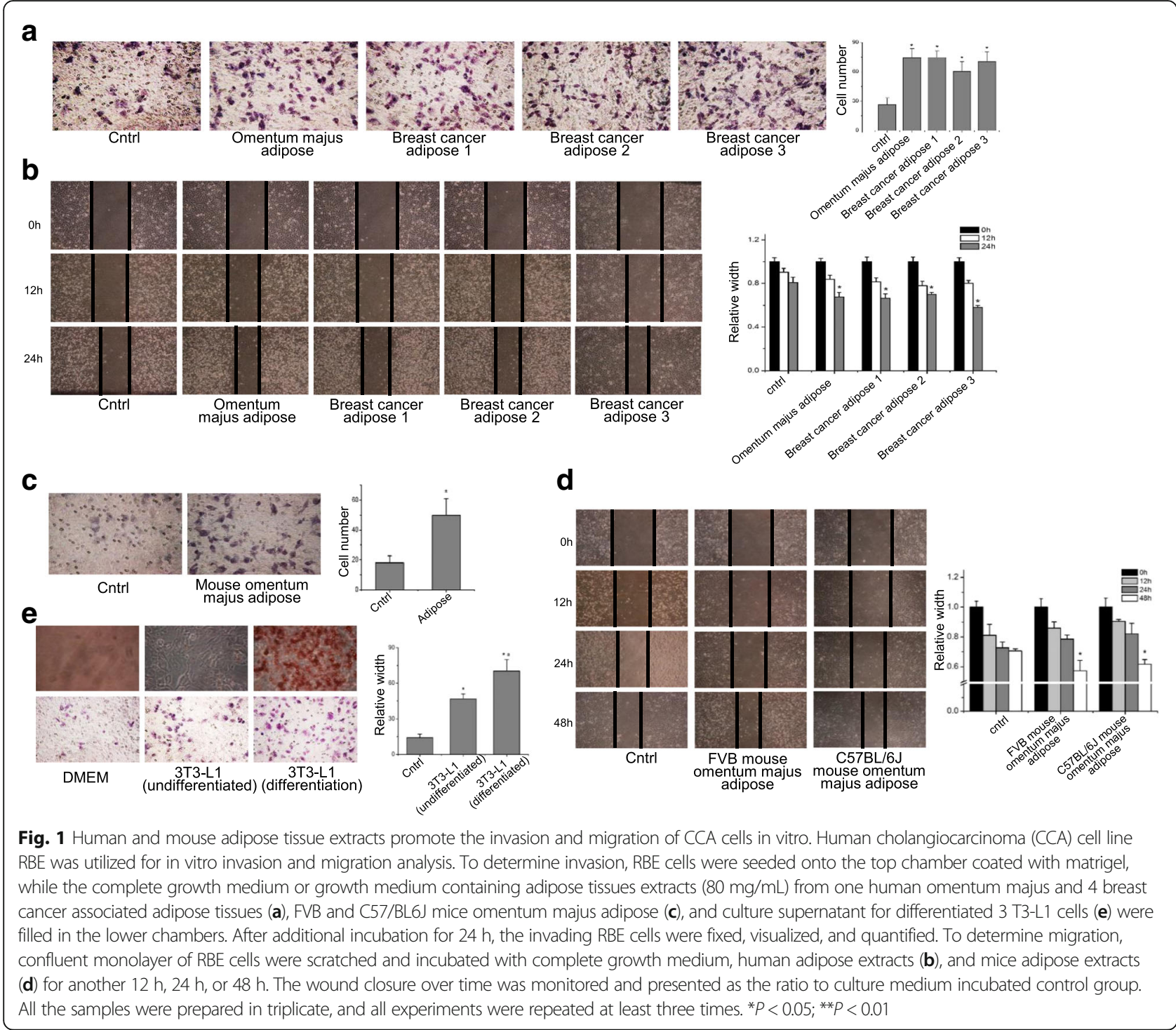

cells $(P<0.05)$. Overall, these results above demonstrated for the first time that crosstalk of CCA cells with adipose tissues and mature adipocytes was essential for CCA metastasis in vitro.

\section{Adipose tissue extracts promote EMT of CCA cells}

EMT is a pivotal mechanism of tumor metastasis in many epithelial malignancies $[7,20]$. In the present study, besides enhanced RBE metastasis in vitro, altered morphologies, from cobblestone-like to typical spindlelike, were found in RBE cells cultivated in adipose tissue extracts (Fig. 2a). To determine whether adipose tissues influence CCA metastasis by regulating EMT signal pathways, we detected related protein markers in RBE cells cultured in the presence or absence of adipose tissue extracts via Western blot assay. Figure $2 b$ and $c$ showed the enhanced EMT phenotype markers in RBE cells cultivated in adipose tissue extracts, including upregulation of matrix metalloproteinase (MMP)-2, MMP-9 and SNAIL, as well as downregulation of E-cadherin and $\beta$ catenin. These findings are consistent with the results of Cadamuro et al., who reported that CCA bile ducts expressed several EMT phenotype markers [33].

Furthermore, we detected significantly enhanced expression of transforming growth factor $\beta 1$ (TGF- $\beta 1$ ) in RBE cells cultured with extracts of adipose tissues from different origins (Fig. 2b, Additional file 1 Figure S5A). TGF- $\beta 1$ is known to promote EMT by inducing SNAIL, and is very important in reprogramming of cellular energy in cancers to satisfy the increased energy demand during EMT to sustain enhanced mobility [34]. Triglycerides (one molecule glycerol plus 3 molecules FA), being the major cellular energy source, are mainly stored in mature adipocytes [35-37]. To investigate whether 


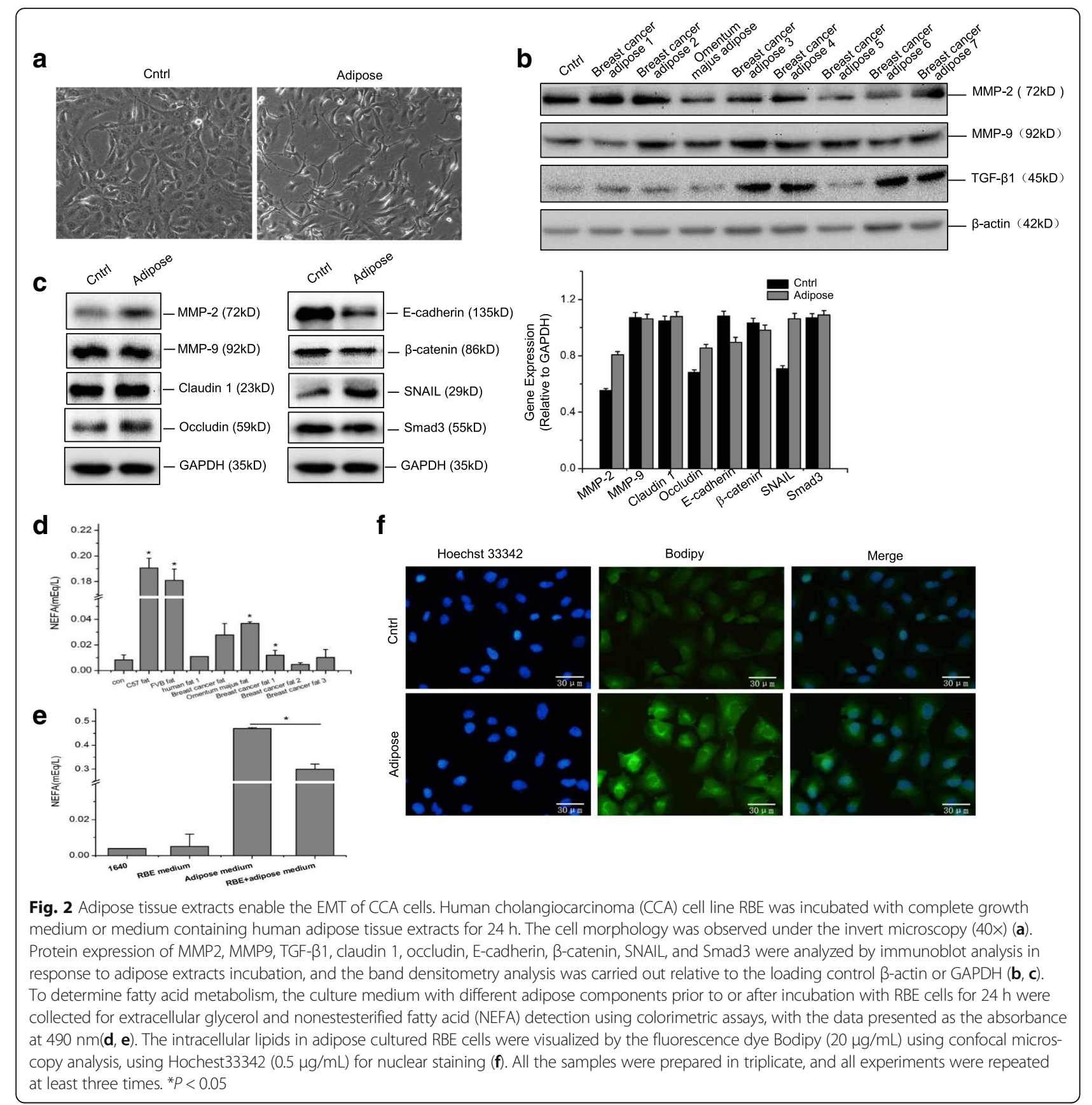

adipose tissue extracts promoted EMT phenotype of CCA cells by affecting cellular energy homeostasis, we examined extracellular glycerol and nonestesterified fatty acid (NEFA) in RBE cells before and after cultivation with different adipose tissue extracts. As shown in Fig. 2d, e and Additional file 1 Figure S1, significantly increased amounts of glycerol and NEFA were detected in the adipose tissue extract-containing culture medium $(P<0.05)$, compared with the regular culture medium. In addition, we found that it is NEFA, rather than glycerol, that was significantly reduced after cultivating RBE cells in culture medium containing adipose tissue extracts (Fig. $2 \mathrm{~d}$ and e, $P<0.05$ ). Moreover, enhanced lipid accumulation was observed in RBE cells cultivated in adipose tissue extracts (Fig. 2f), consistent with findings suggesting that FA plays a key role in certain pathological processes by promoting cancer cell lipogenesis $[38,39]$. Overall, the results above indicated that 
adipose tissue facilitates EMT of CCA cells in vitro, likely by providing NEFAs as energy source.

Adipose tissue extracts enhance CCA metastasis in nude mice The influence of adipose tissues on CCA metastasis was further confirmed in vivo in CCA metastasis Balb/C nude mouse model (Fig. 3a). First, $48 \mathrm{~h}$ after inoculation, distribution and accumulation of RBE cells were visualized using an in vivo imaging system. As shown in Fig. $3 \mathrm{~b}$ and c, significantly increased fluorescence signals were detected in the liver and kidney of mice injected with RBE cells cultivated in adipose tissue extracts, compared with mice injected with RBE cells under normal culture conditions $(P<0.05)$. However, the chemical compound BMS309403, which could specifically inhibit FA uptake in vitro [40], compromised the adipose-induced CCA metastasis in vivo, especially in the kidney $(P<0.05)$.

One month after inoculation, $40 \%(2 / 5)$ of the mice injected with RBE cells cultivated in adipose tissue extracts developed liver metastasis, in which the hepatocytes manifested typical pathologic characters, such as irregular shape, variable sizes, hyperchromatic and pleomorphic nuclei, nuclear disintegration and increased proliferation (Fig. 3d). Moreover, no distance metastasis and obviously suppressed cancer proliferation were observed in BMS309403 plus adipose tissue-cultivated RBE injected mice, compared with adipose tissue extract-cultivated RBE group (Fig. 3d). The results above are consistent with the in vitro data showing that adipose tissue can promote CCA metastasis.

\section{FABP4 is involved in CCA metastasis}

Based on the data above, we speculated that FAs released by adipocytes might at least be involved in adipose-induced CCA metastasis. However, free FAs are relatively insoluble and potentially toxic, and they require non-catalytic binding proteins to perform their biological functions [41]. FABPs are a family of intracellular proteins that exhibit high affinity for noncovalent binding to long-chain FAs [40]. In the present study, we detected the expression of FABP1-7 in RBE cultured with/without adipose tissue extracts by qRT-PCR assay. The result revealed that adipose coculture significantly enhanced the expression of FABP5 and

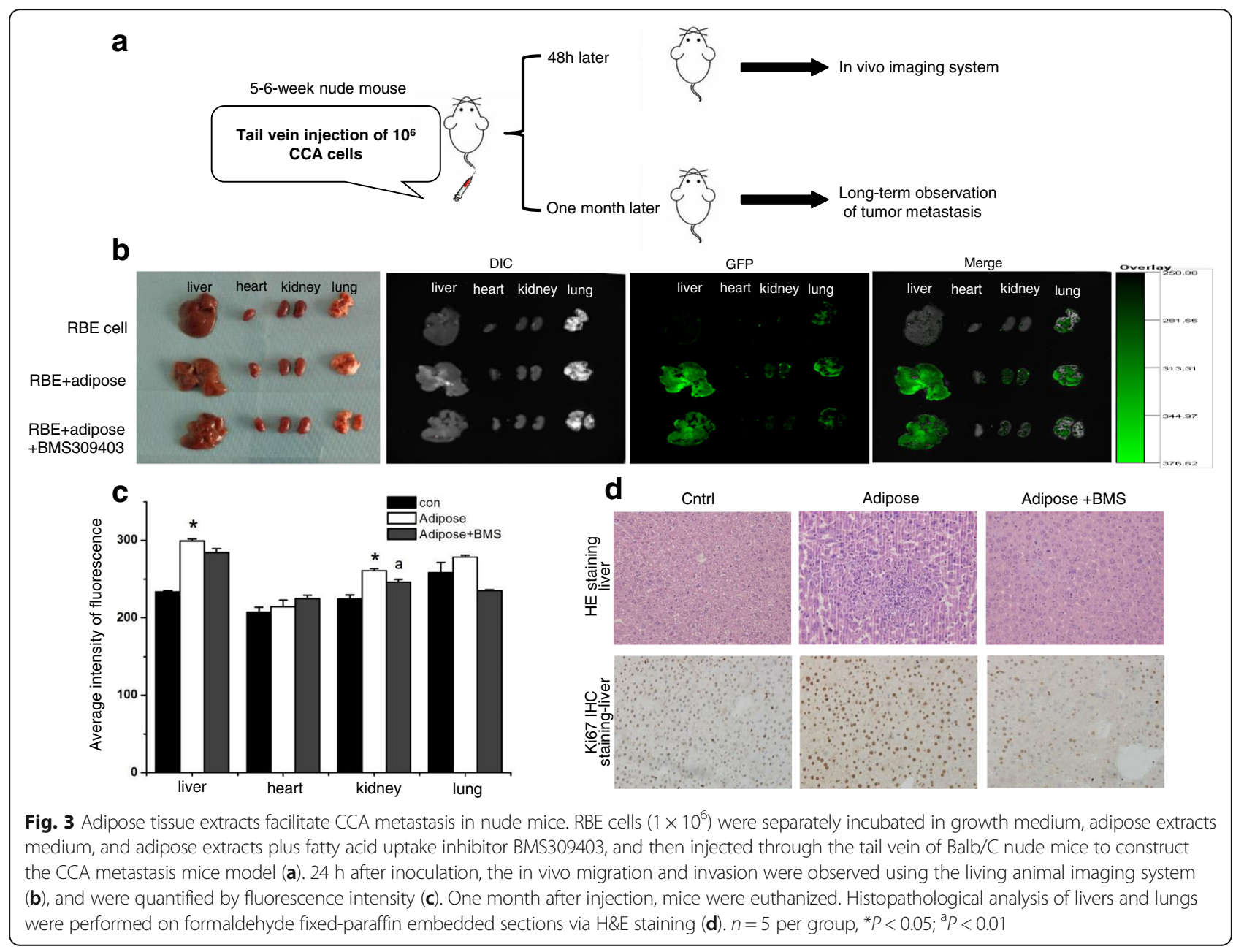


FABP4, while decreased FABP1 expression in RBE cells, as compared with cells cultured in normal complete medium (Fig. 4a). We noticed that, of these three FABPs, FABP4 was the most enriched one in RBE cells under normal culture condition. Because FABP4 has been regarded as an essential adipokine mostly derived from adipocytes [41], it was chosen for further study in the present work.

As expected, we demonstrated that FABP4 highly expressed in human omentum adipose and mature adipocytes, but not in human CCA tissues or cell lines (Fig. 4b and Additional file 1 Figure S2). Coincidently, human CCA tissues were shown to containing more adipocytes than non-cancerous tissues (Fig. 4c). Taken together the finding that synthesized EGFP-tagged FABP4 protein could be taken up by CCA cells (Fig. 4d), we speculated that the adipocyte-derived FABP4 might play a role in mediating adipocyte-induced CCA metastasis.

\section{FABP4 inhibition disrupts adipocyte-induced CCA metastasis} and EMT

To test our above hypothesis, we used the specific FABP4 inhibitor BMS309403 in the following study
(Additional file 1 Figure S3A). BMS309403 effectively inhibited the lipid accumulation in both adiposecocultured RBE and Hccc-9810 cells (Additional file 1 Figure S6, Fig. 5a, 6a), and significantly suppressed the adipose-induced CCA invasion and migration in vitro. For example, the number of invading RBE cells cultivated in adipose tissue extracts was nearly 2 -fold of that in control. This trend can be completely reversed by adding FABP4 inhibitor to the adipose tissue extractcontaining medium (Fig. 5b). Moreover, the promoted migration of RBE cells cultured with adipose tissue extracts could be suppressed by BMS309403 treatment (Fig. 5c). A similar tendency was observed in Hccc-9810 cells as well (Fig. 6).

Western blot assay results showed that MMP-2, MMP-9 and the EMT-associated SNAIL transcription factor were upregulated, whereas the tight junction proteins claudin 1 and occludin were downregulated. Moreover, E-cadherin and $\beta$-catenin were suppressed in RBE cells cultivated in adipose tissue extracts compared with that in parental RBE cells (Fig. 5d). However, the BMS309403 treatment completely reversed

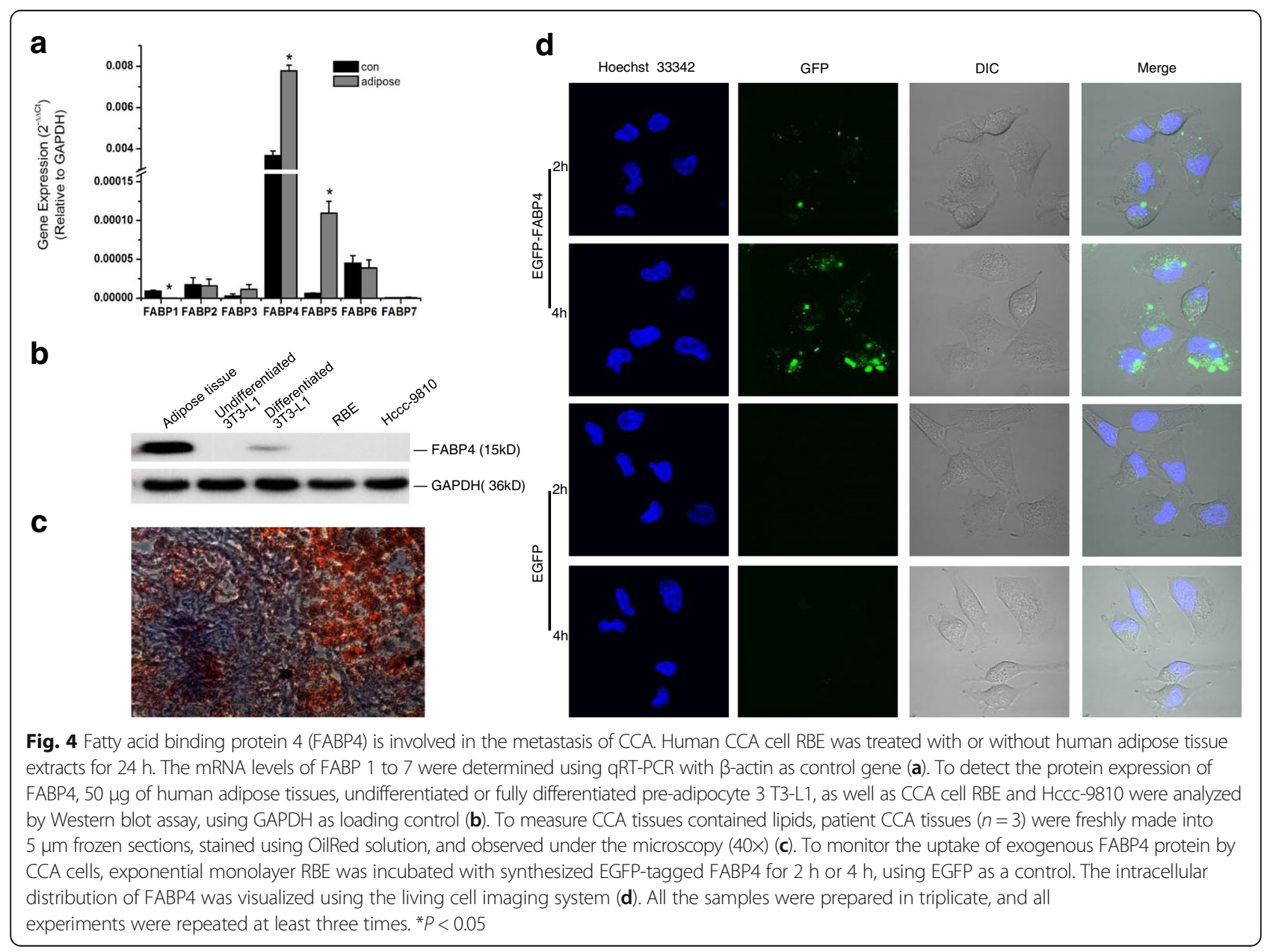




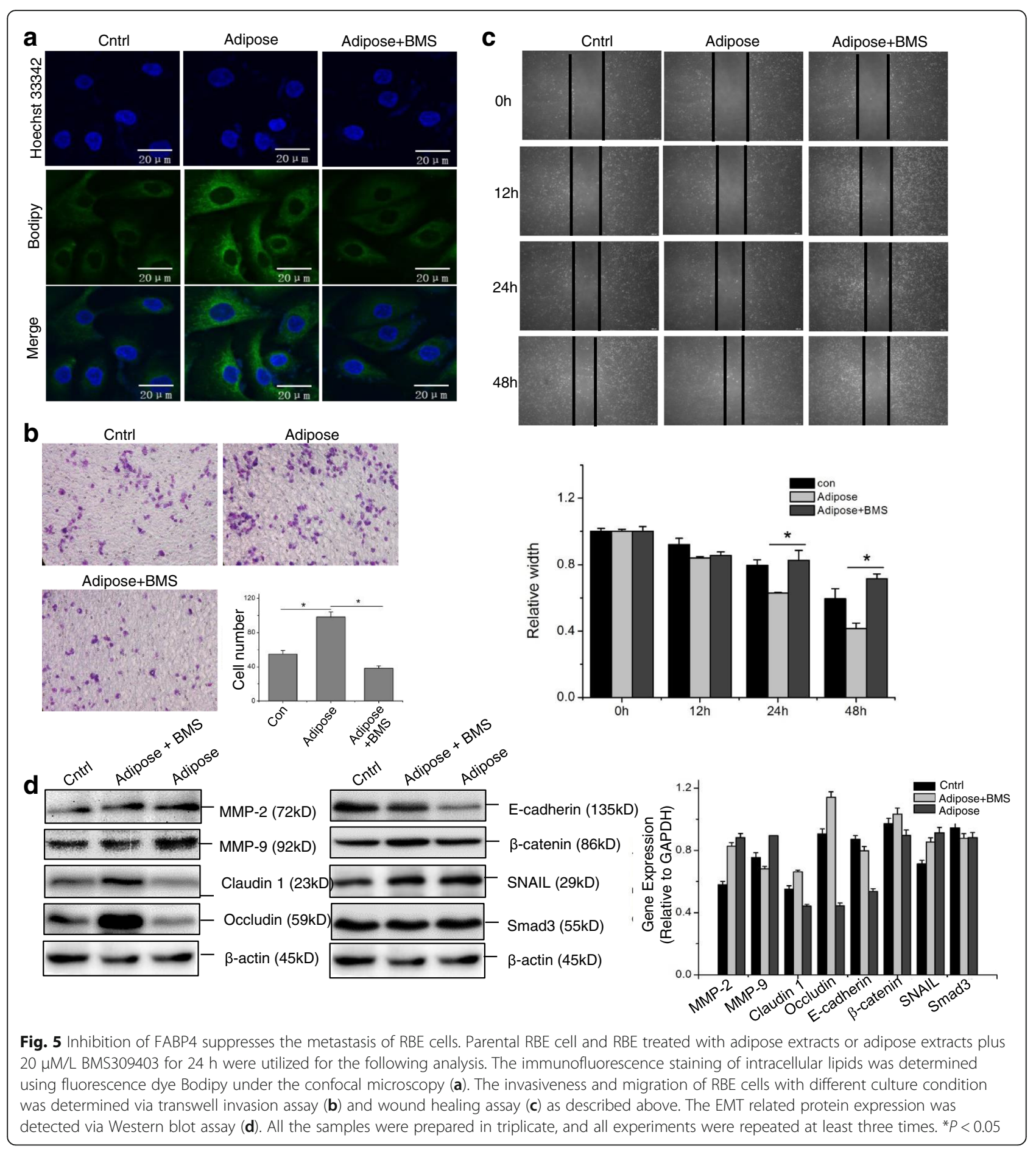

the expression patterns of the above mentioned EMT marker proteins.

FABP4 overexpression enhances EMT and adipocyte-induced CCA metastasis

To further confirm the role of FABP4 in CCA metastasis, FABP4 recombinant adenovirus was used to demonstrate the involvement of FABP4 in adipocyte-modulated CCA progression (Additional file 1: Figure S3). FABP4 overexpression enhanced the intracellular lipid accumulation, increased the number of invading cells and the rate of wound healing both in RBE and Hccc-9810 cells (Figs. 7 and 8), and promoted the early metastasis of RBE cells in vivo (Additional file 1 Figure S4). Expressions of EMT- 


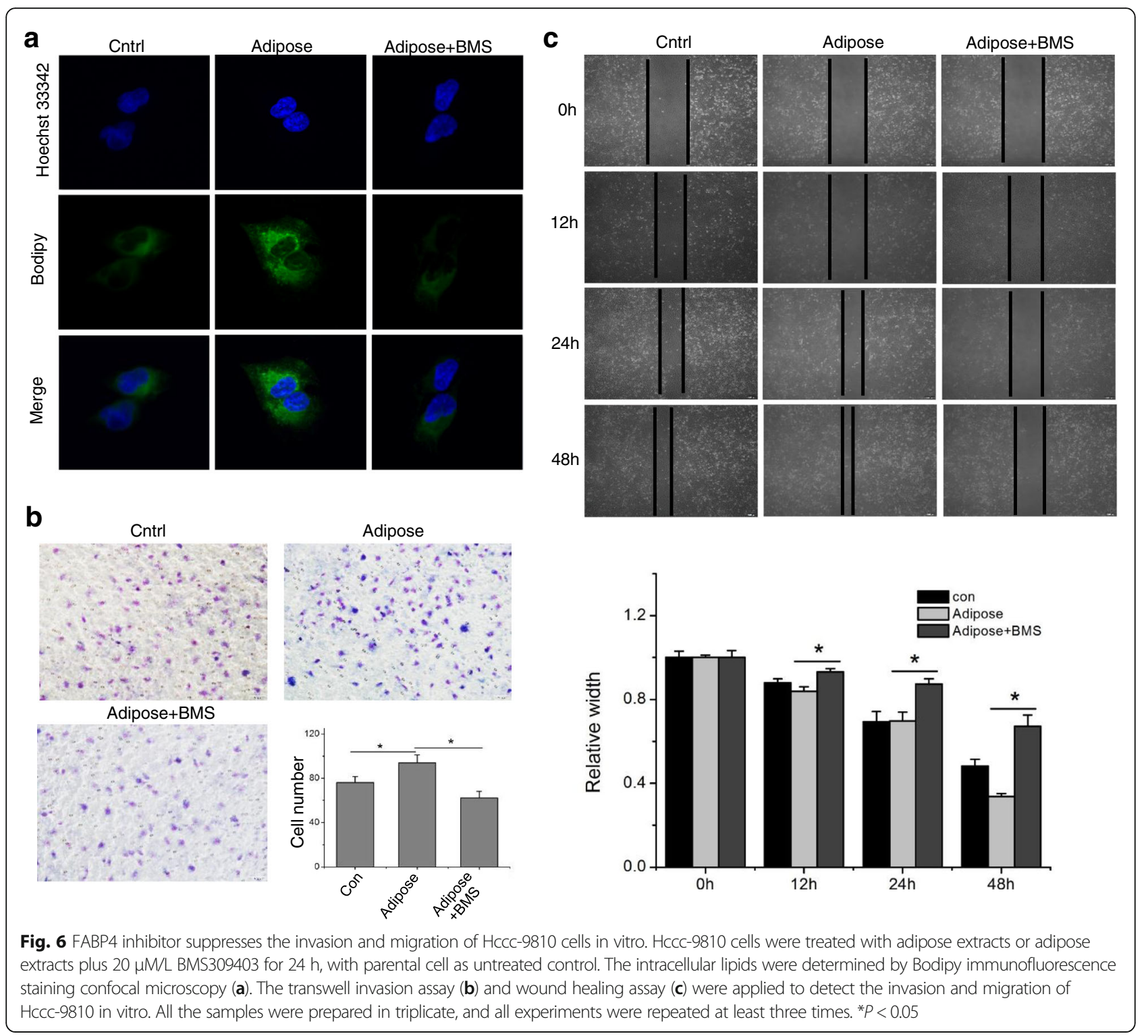

related protein markers were examined in FABP4overexpressing RBE cells via Western blot assay. As expected, FABP4 overexpression further boosted the expression levels of MMP-2 and SNAIL, whereas it inhibited the expressions of tight junction protein and E-cadherin $/ \beta$-catenin proteins, compared with that in adenovirus vector control group (Fig. 7d). However, despite these differences, no obvious variations in Smad3 was detected in all the treatments (Fig. 5d and 7d). These results collectively indicated that FABP4 was involved in adipose tissue-mediated CCA metastasis.

\section{Discussion}

As the major components of adipose, adipocytes play a key role not only in controlling metabolism homeostatic, but also in mediating several pathological processes by releasing lipids and mitogenic and proinflammatory factors [42]. Lately, cancer-associated adipocytes have been shown to regulate tumor progression in hepatocarcinoma [43], ovarian, and breast cancers [18, 25, 32, 44]. Several reports have indicated that adipose tissues from different anatomic location may produce different cytokines and growth factors, therefore they behave not exactly the same way $[45,46]$. Especially in couple of breast cancer studies, estrogen receptor positive $\left(E R^{+}\right)$ adipose tissues obtained from breast cancers were found to behave differently in $\mathrm{ER}^{+}$breast cancer cell line MCF7, as compared to adipose from normal breast [26, 47].

However, we demonstrated in the present study that different adipose tissue and mature adipocytes 

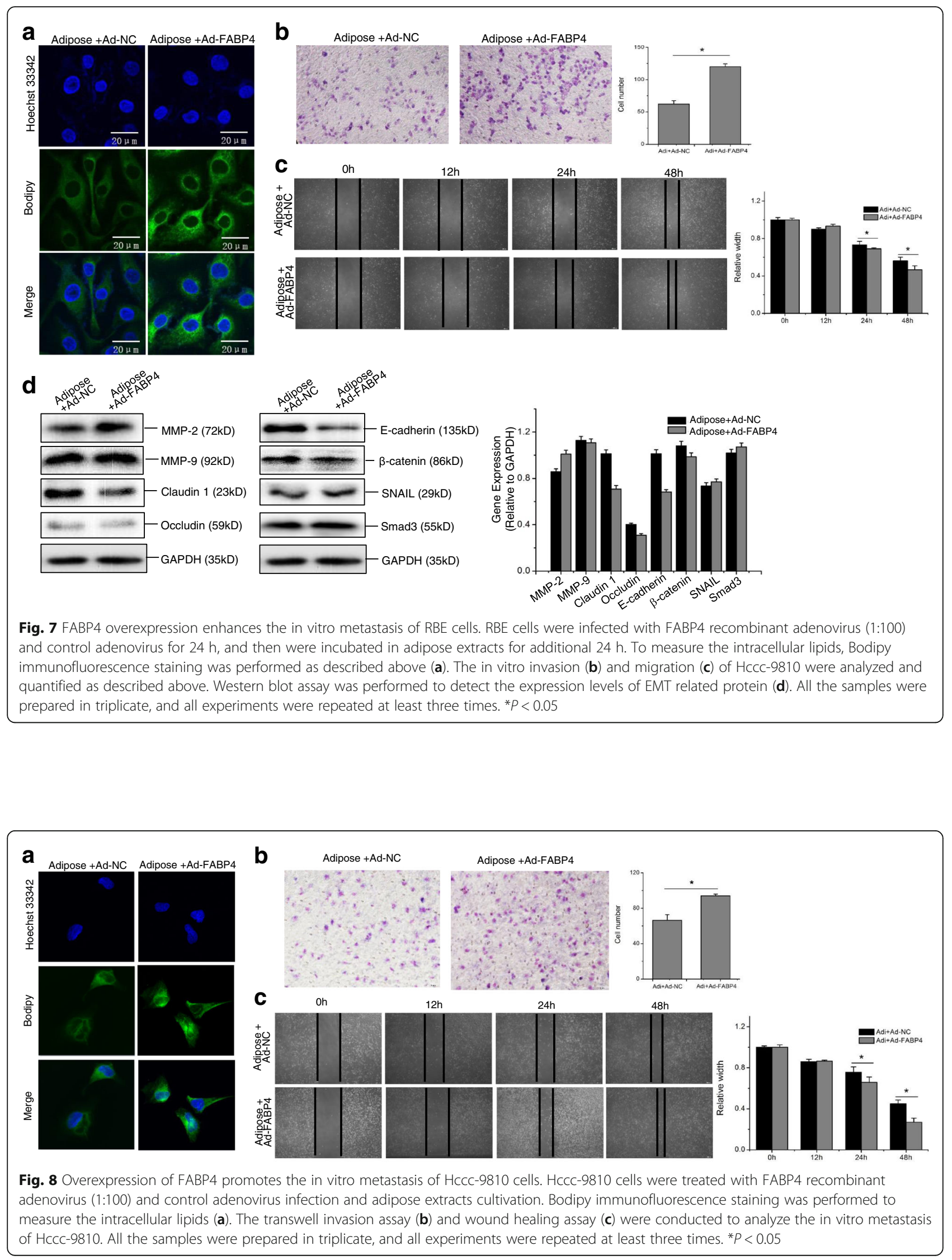


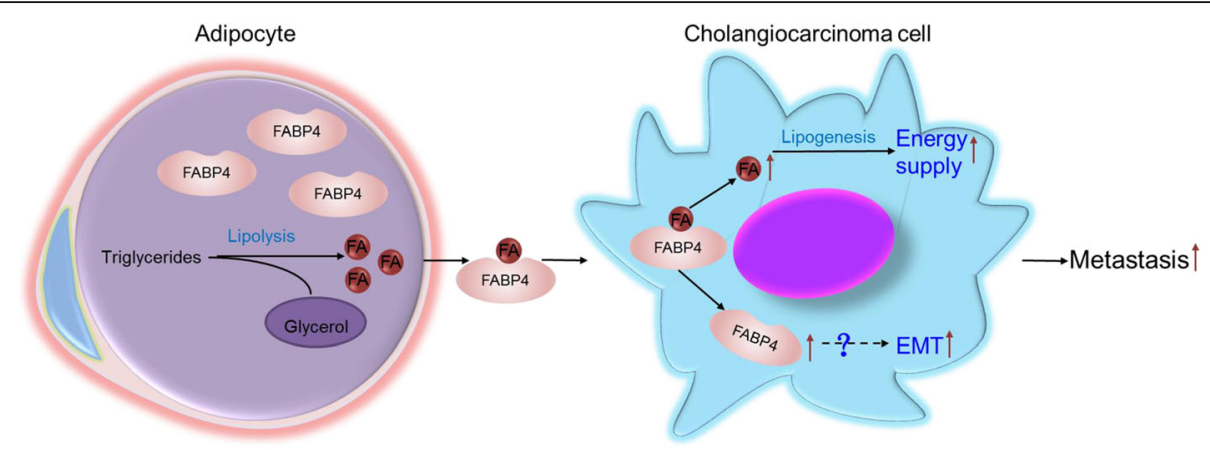

Fig. 9 Adipocytes interact with cholangiocarcinoma cells to induce metastasis in cancer cells. FABP4 mediates the increased adipocyte-derived FAs absorption in CCA cells, providing energy for more aggressive phenotypes in CCA. Furthermore, adipocytes-derived FABP4 itself plays a regulatory role in CCA metastasis

significantly enhanced the invasion and migration of CCA both in vitro and in vivo, regardless of the species and anatomical locations from which the adipose tissues were isolated. Considering that the biological effects of adipocytes on CCA cells are remain unknown, we speculated that certain potential mechanisms complementary to the known ones might at least be involved in adipocyte induced CCA metastasis.

The involvement of adipocytes in tumor progression was thought to be mediated via regulating factors involved in matrix remodeling, invasion and survival of cancer cells, as well as inducing EMT [15]. EMT is a dynamic process, through which epithelial cells structurally and functionally gain the mesenchymal characteristics, and has lately been regarded as a pivotal mechanism for tumor metastatic dissemination [7, 20, 21]. During this process, EMT-inducing transcription factors (SNAIL, ZEB and TWIST etc.) regulate the expressions of Ecadherin and $\beta$-catenin, as well as genes associated with mesenchymal phenotypes including $\mathrm{N}$-cadherin, vimentin, fibronectin, $\alpha$-smooth muscle actin ( $\alpha$-SMA) and MMPs, which leads to the formation of several migratory structures and the degradation of the extracellular matrix [21, 48, 49]. Together with the compromised tight junction, a repressed epithelial phenotype is finally replaced by an activated mesenchymal phenotype, which enables the tumor cells with invasive properties to spread toward other tissues/organs $[21,49]$.

In CCA, several reports have shown that cancerassociated fibroblasts and tumor-associated macrophages play key roles in CCA progression [21]. However, the present study is the first one to report that co-culture with adipocytes could induce the representative mesenchymal properties in CCA cells, which resulted in alterations in cell polarity, cell shape, loss of cell-to-cell adhesion regulated by E-cadherin, and expressions of mesenchymal biomarkers, indicating the acquired EMT induced by CCA associated adipocytes.
Typically, cancer cells are characterized with accelerated proliferation and aggressive phenotypes, therefore they demand enhanced energy metabolism by increasing de novo lipogenesis $[50,51]$. When de novo lipogenesis is inhibited in some cases $[52,53]$, the adipocytes from the tumor microenvironment are known to serve as a major source to provide exogenous lipids for survival of tumor cells [54]. For example, adipocytes-derived FAs are known to serve as economical and important lipid sources to meet the higher energy requirement for enhanced mobility of ovarian cancer cells [55]. In the present study, the increased uptake of FAs and enhanced intracellular lipid accumulation were observed in adipose extract-co-cultured CCA cells, which present typical EMT phenotype. These results indicated that adipocyte-derived FAs might be one of the regulators potentially involved in adipocyte-induced EMT in CCA, which are consistent with previous study that free FAs exacerbate the EMT phenotypes in hepatocellular carcinoma cells [56].

However, relatively insoluble free FAs require noncatalytic binding proteins to perform the biological functions mentioned above [41]. In the present study, we found certain members of fatty acid binding protein family might be involved in this process. For example, significantly increased adipocyte FABP (FABP4) and epithelial FABP (FABP5), as well as suppressed liver FABP (FABP1) in adipose cocultured CCA cells. Firstly identified in liver tissues, FABP1 was thought to be vital for hepatic $\beta$-oxidation of unesterified fatty acid, and FABP1 downregulation was reported to be associated with hepatic stellate cells activation, proliferation, and secretion of collagen and extracellular matrix protein, which would finally lead to fibrogenesis [57]. FABP5 expression was proved to be detectable in endothelial cells, lung epithelium, macrophages, adipocytes, and breast cancer cells [57]. FABP5 Upregulation has been related to promoted cancer cell proliferation and metastasis, therefore FABP5 also known as oncogenic FABP [57]. These 
evidences indicated that FABP1 and FABP5 might be possible regulatory mechanisms in adipocyte-induced CCA metastasis.

However, FABP4 was selected for further analysis in the present work. Because FABP4 mainly presents in adipose tissues or mature adipocytes, possesses the highest affinity among all FABPs for both saturated and unsaturated FAs, and its functions in intracellular metabolism homeostasis and immunometabolic diseases are the best characterized [41]. Besides, FABP4 has also been shown to be an adipose-derived cytokine that could be released into circulation [41, 58], and involved in cancer cell growth and metastasis in multiple malignancies [18, 41, 59]. For example, Nieman et al. observed highly expressed FABP4 in omental metastases but not in primary ovarian cancers [18]; Uehara et al. also reported that FABP4 could promote human prostate cancer cell progression by binding to FAs [59]. In the present study, both in vitro and in vivo data clearly showed that the adipocyte-derived FABP4 mediates the adipose-induced intracellular lipid accumulation, invasion, migration, and EMT in CCA cells, at least by acting as FA transporter between adipocytes and tumor cells (Fig. 9).

\section{Conclusions}

In summary, our current study, for the first time, demonstrates the roles of FABP4 in adipocyte-CCA interactions, as well as in the energy extraction of CCA cells from cancer related adipocytes. FABP4 mediates the adipocyte-induced invasion, migration and EMT of CCA cells. Since the selective inhibitor of FABP4 blocks FABP4-mediated regulation on CCA metastasis, our findings provide a potential therapeutic target to interfere with CCA metastasis. However, CCA is a very complex and heterogeneous tumor with the prominent stromal components, therefore the EMT signaling could be activated through a large number of mechanisms, strong efforts and further experiments are eagerly needed to define the downstream signaling cascades of FABP4 involvement in adipocyte-induced EMT of CCA cells.

\section{Additional file}

Additional file 1: Figure S1. Glycerol colorimetric assay. Human cholangiocarcinoma (CCA) cell line RBE was incubated in complete growth medium or adipose tissue extracts $(80 \mathrm{mg} / \mathrm{mL})$ supplemented medium for $24 \mathrm{~h}$. The culture medium were collected prior to or after cell culture for extracellular glycerol detection using colorimetric assays, with the data presented as the absorbance at $490 \mathrm{~nm}(\mathrm{~A}, \mathrm{~B})$. All the samples were prepared in triplicate, and all experiments were repeated at least three times. ${ }^{*} P<0.05$. Figure $\mathbf{S 2}$. The expression of FABP4 protein CCA cell RBE. Immunohistochemistry staining of FABP4 expression in cholangiocarcinoma tissue array. Human CCA tissue microarray was obtained from Outdo Biotech Co., Ltd. (Shanghai, China). The FABP4 antibody (EPR3579, Abcam, MA, USA, 1:200) was used for IHC staining. Figure S3. FABP4 expression in RBE and Hccc-9810 cells. Human CCA cell line RBE (A) and Hccc-9810 (B) were treated with BMS309403 $(20 \mathrm{mg} / \mathrm{mL}$ or $40 \mathrm{mg} / \mathrm{mL}$ ) for $24 \mathrm{~h}$, as the same time these cell lines were infected with recombinant FABP4 adenovirus or control virus (1:10, 1:100), and mRNA expression of FABP4 was determined and are expressed relative to $\beta$-actin. All the samples were prepared in triplicate, and all experiments were repeated at least three times. ${ }^{*} P<0.05$. Figure $\mathbf{S 4}$. FABP4 overexpression affects CCA metastasis in vivo. $1 \times 10^{6}$ RBE cells were infected with recombinant FABP4 adenovirus or control virus (1:10, 1:100) for $24 \mathrm{~h}$, and incubated in adipose extracts medium for additional $24 \mathrm{~h}$ prior to tail vein injection of Balb/C nude mice. The in vivo migration and invasion of RBE cells were observed under the living animal imaging system $24 \mathrm{~h}$ after inoculation (A), and were quantified by fluorescence intensity (B). The mice were euthanized one month after injection. The livers and lungs were fixed in formaldehyde, embedded by paraffin, made into $4 \mu \mathrm{m}$ sections, and stained using H\&E assay (C). $n=5$ per group, ${ }^{*} P<0.05$. Figure S5. Quantification of Western blot. The protein expression of TGF- $\beta$ of RBE cells cocultured with different adipose tissues(A), and FABP4 in different samples (B) was quantified using Image J. The band densitometry analysis was carried out relative to the loading control $\beta$-actin. ${ }^{*} P<0.05$. Figure $\mathbf{S 6}$.

Quantification of Bodipy staining. The intracellular lipids in adipose cocultured RBE cells (A), BMS309403 treated RBE cells (B), BMS309403 treated Hccc-9810 cells (C), FABP4 over-expressed RBE cells (D), and FABP4 over-expressed Hccc-9810 cells (E) were visualized by the fluorescence dye Bodipy $(20 \mu \mathrm{g} / \mathrm{mL})$, followed by fluorescence intensity analysis using Image J. All the samples were prepared in triplicate, and all experiments were repeated at least three times. ${ }^{*} P<0.05$. (DOCX $2322 \mathrm{~kb})$

\section{Acknowledgements}

This work was supported by grants from the National Science Foundation of China (81773226, 81402627, 81522039, and 81502038), China postdoctoral science foundation (2017 M611908), A Project Funded by the Priority Academic Program Development of Jiangsu Higher Education Institutions(PAPD), and Key Research and Development Program of China (2016YFC0904702 \& 2016YFC0904700).

\section{Authors' contributions}

YJ and SYZ conceived and designed the study. JHN and JYZ carried out the molecular biology studies. JHN and LLW drafted the manuscript and the Figs. LJL, MFA and QY collected the serum samples. JHN and LLW performed the statistical analysis. YJ and SYZ modified the manuscript. All authors read and approved the final manuscript.

\section{Competing interests}

The authors declare no conflicts of interest.

\section{Publisher's Note}

Springer Nature remains neutral with regard to jurisdictional claims in published maps and institutional affiliations.

\section{Author details}

'Department of Radiation Genetics, School of Radiation Medicine and Protection, Medical College of Soochow University, Suzhou 215123, China. ${ }^{2}$ Collaborative Innovation Center of Radiological Medicine of Jiangsu Higher Education Institutions, Suzhou 215123, China. ${ }^{3}$ Department of Toxicology, School of Public Health, Medical College of Soochow University, Suzhou 215123, China. ${ }^{4}$ Department of Radiotherapy, First Affiliate Hospital of Soochow University, Suzhou 215123, China. ${ }^{5}$ Department of Gastroenterology, Wuxi People's Hospital Affiliated to Nanjing Medical University, Wuxi 214002, China.

Received: 4 September 2017 Accepted: 17 November 2017

Published online: 13 December 2017

References

1. Razumilava N, Gores GJ. Cholangiocarcinoma. Lancet. 2014;383:2168-79. doi: 10.1016/S0140-6736(13)61903-0.

2. Everhart JE, Ruhl CE. Burden of digestive diseases in the United States part III: liver, biliary tract, and pancreas. Gastroenterology. 2009;136:1134-44. doi:10.1053/j.gastro.2009.02.038. 
3. Khan SA, Toledano MB, Taylor-Robinson SD. Epidemiology, risk factors, and pathogenesis of cholangiocarcinoma. HPB (Oxford). 2008;10:77-82. doi:10. 1080/13651820801992641.

4. Khan SA, Davidson BR, Goldin RD, Heaton N, Karani J, Pereira SP, Rosenberg WM, Tait P, Taylor-Robinson SD, Thillainayagam AV, Thomas HC, Wasan H. British Society of G. Guidelines for the diagnosis and treatment of cholangiocarcinoma: an update. Gut. 2012;61:1657-69. doi:10.1136/gutjnl2011-301748.

5. Hezel AF, Deshpande V, Zhu AX. Genetics of biliary tract cancers and emerging targeted therapies. J Clin Oncol. 2010;28:3531-40. doi:10.1200/ JCO.2009.27.4787.

6. Patel T. Cholangiocarcinoma-controversies and challenges. Nat Rev Gastroenterol Hepatol. 2011;8:189-200. https://doi.org/10.1038/nrgastro.2011.20.

7. Brivio S, Cadamuro M, Fabris L, Strazzabosco M. Epithelial-to-mesenchymal transition and cancer invasiveness: what can we learn from cholangiocarcinoma? J Clin Med. 2015;4:2028-41. doi:10.3390/jcm4121958.

8. Yoshikawa D, Ojima H, Iwasaki M, Hiraoka N, Kosuge T, Kasai S, Hirohashi S, Shibata T. Clinicopathological and prognostic significance of EGFR, VEGF, and HER2 expression in cholangiocarcinoma. Br J Cancer. 2008;98:418-25. doi:10.1038/sj.bjc.6604129.

9. Oyasiij T, Zhang J, Kuvshinoff B, lyer R, Hochwald SN. Molecular targets in biliary carcinogenesis and implications for therapy. Oncologist. 2015;20:742-51. https:/doi.org/10.1634/theoncologist.2014-0442.

10. Yang B, House MG, Guo M, Herman JG, Clark DP. Promoter methylation profiles of tumor suppressor genes in intrahepatic and extrahepatic cholangiocarcinoma. Mod Pathol. 2005;18:412-20. https://doi.org/10.1038/ modpathol.3800287.

11. Lee S, Kim WH, Jung HY, Yang MH, Kang GH. Aberrant CpG island methylation of multiple genes in intrahepatic cholangiocarcinoma. Am J Pathol. 2002;161:1015-22. https://doi.org/10.1016/S0002-9440(10)64262-9.

12. Tischoff I, Wittekind $C$, Tannapfel A. Role of epigenetic alterations in cholangiocarcinoma. J Hepato-Biliary-Pancreat Surg. 2006;13:274-9. doi:10. 1007/s00534-005-1055-3.

13. Kim BH, Cho NY, Choi M, Lee S, Jang JJ, Kang GH. Methylation profiles of multiple CpG island loci in extrahepatic cholangiocarcinoma versus those of intrahepatic cholangiocarcinomas. Arch Pathol Lab Med. 2007;131:923-30. https://doi.org/10.1043/1543-2165(2007)131[923:MPOMCI]2.0.CO;2.

14. Hamilton JP. Epigenetic mechanisms involved in the pathogenesis of hepatobiliary malignancies. Epigenomics. 2010;2:233-43.doi: 10.2217/epi.10.9.

15. Bussard KM, Mutkus L, Stumpf K, Gomez-Manzano C, Marini FC. Tumorassociated stromal cells as key contributors to the tumor microenvironment. Breast Cancer Res. 2016;18:84. doi:10.1186/s13058-016-0740-2.

16. Khandekar MJ, Cohen P, Spiegelman BM. Molecular mechanisms of cancer development in obesity. Nat Rev Cancer. 2011;11:886-95. doi:10.1038/nrc3174.

17. Varmus $\mathrm{H}$, Harlow $\mathrm{E}$. Science funding: provocative questions in cancer research. Nature. 2012;481:436-7. doi:10.1038/481436a.

18. Nieman KM, Kenny HA, Penicka CV, Ladanyi A, Buell-Gutbrod R, Zillhardt MR, Romero IL, Carey MS, Mills GB, Hotamisligil GS, Yamada SD, Peter ME, Gwin $\mathrm{K}$, et al. Adipocytes promote ovarian cancer metastasis and provide energy for rapid tumor growth. Nat Med. 2011;17:1498-503. doi:10.1038/nm.2492.

19. Prieto-Hontoria PL, Perez-Matute P, Fernandez-Galilea M, Bustos M, Martinez JA, Moreno-Aliaga MJ. Role of obesity-associated dysfunctional adipose tissue in cancer: a molecular nutrition approach. Biochim Biophys Acta. 2011;1807:664-78. doi:10.1016/j.bbabio.2010.11.004.

20. Thiery JP, Acloque H, Huang RY, Nieto MA. Epithelial-mesenchymal transitions in development and disease. Cell. 2009;139:871-90. doi:10.1016/j.cell.2009.11.007.

21. Vaquero J, Guedj N, Claperon A, Nguyen Ho-Bouldoires TH, Paradis V, Fouassier L. Epithelial-mesenchymal transition in cholangiocarcinoma: from clinical evidence to regulatory networks. J Hepatol. 2017;66:424-41. doi:10. 1016/j.jhep.2016.09.010

22. Iser IC, Ceschini SM, Onzi GR, Bertoni AP, Lenz G, Wink MR. Conditioned medium from adipose-derived stem cells (ADSCs) promotes epithelial-tomesenchymal-like transition (EMT-like) in glioma cells in vitro. Mol Neurobiol. 2016:53:7184-99. https://doi.org/10.1007/s12035-015-9585-4.

23. Lee $Y$, Jung WH, Koo JS. Adipocytes can induce epithelial-mesenchymal transition in breast cancer cells. Breast Cancer Res Treat. 2015;153:323-35. doi:10.1007/s 10549-015-3550-9.

24. Amemori S, Ootani A, Aoki S, Fujise T, Shimoda R, Kakimoto T, Shiraishi R, Sakata Y, Tsunada S, Iwakiri R, Fujimoto K. Adipocytes and preadipocytes promote the proliferation of colon cancer cells in vitro. Am J Physiol Gastrointest Liver Physiol. 2007;292:G923-9. doi:10.1152/ajpgi.00145.2006.
25. Tan J, Buache E, Chenard MP, Dali-Youcef N, Rio MC. Adipocyte is a nontrivial, dynamic partner of breast cancer cells. Int J Dev Biol. 2011;55:851-9. doi: 10.1387/ijdb.113365jt.

26. Fletcher SJ, Sacca PA, Pistone-Creydt M, Colo FA, Serra MF, Santino FE, Sasso CV, Lopez-Fontana CM, Caron RW, Calvo JC, Pistone-Creydt V. Human breast adipose tissue: characterization of factors that change during tumor progression in human breast cancer. J Exp Clin Cancer Res. 2017;36:26. doi:10.1186/s13046-017-0494-4

27. Ito R, Narita S, Huang M, Nara T, Numakura K, Takayama K, Tsuruta H, Maeno A, Saito M, Inoue T, Tsuchiya N, Satoh S, Habuchi T. The impact of obesity and adiponectin signaling in patients with renal cell carcinoma: a potential mechanism for the "obesity paradox". PLoS One. 2017;12:e0171615. doi:10.1371/journal.pone.0171615.

28. Zi X, Lusch A, Blair CA, Okhunov Z, Yokoyama NN, Liu S, Baker M, Huynh V, Landman J. Effect of perineoplasm perinephric adipose tissues on migration of clear cell renal cell carcinoma cells: a potential role of WNT signaling. Oncotarget. 2016;7:53277-88. 10.18632/oncotarget.10467.

29. Li JS, Han TJ, Jing N, Li L, Zhang XH, Ma FZ, Liu JY. Obesity and the risk of cholangiocarcinoma: a meta-analysis. Tumour Biol. 2014;35:6831-8. doi:10. 1007/s13277-014-1939-4

30. Jiao Y, Zhang J, Lu L, Xu J, Qin L. The Fto gene regulates the proliferation and differentiation of pre-adipocytes in vitro. Nutrients. 2016;8:102. doi:10.3390/nu8020102.

31. Jiao Y, Liu C, Cui FM, JY X, Tong J, Qi XF, Wang LL, Zhu W. Long intergenic non-coding RNA induced by $X$-ray irradiation regulates DNA damage response signaling in the human bronchial epithelial BEAS-2B cell line. Oncol Lett. 2015;9:169-76. doi:10.3892/ol.2014.2622.

32. Dirat B, Bochet L, Dabek M, Daviaud D, Dauvillier S, Majed B, Wang YY, Meulle A, Salles B, Le Gonidec S, Garrido I, Escourrou G, Valet P, et al. Cancer-associated adipocytes exhibit an activated phenotype and contribute to breast cancer invasion. Cancer Res. 2011;71:2455-65. doi:10.1158/0008-5472.CAN-10-3323.

33. Cadamuro M, Nardo G, Indraccolo S, Dall'olmo L, Sambado L, Moserle L, Franceschet I, Colledan M, Massani M, Stecca T, Bassi N, Morton S, Spirli C, et al. Platelet-derived growth factor-D and rho GTPases regulate recruitment of cancer-associated fibroblasts in cholangiocarcinoma. Hepatology. 2013; 58:1042-53. doi:10.1002/hep.26384.

34. Jiang L, Deberardinis $R$, Boothman DA. The cancer cell 'energy grid': TGFbeta1 signaling coordinates metabolism for migration. Mol Cell Oncol. 2015; 2:e981994. https://doi.org/10.4161/23723556.2014.981994.

35. Bosy-Westphal A, Kahlhofer J, Lagerpusch M, Skurk T, Muller MJ. Deep body composition phenotyping during weight cycling: relevance to metabolic efficiency and metabolic risk. Obes Rev. 2015;16(Suppl 1):36-44. doi:10.1111/ obr.12254.

36. Zamboni M, Rossi AP, Fantin F, Zamboni G, Chirumbolo S, Zoico E, Mazzali G. Adipose tissue, diet and aging. Mech Ageing Dev. 2014;136-137:129-37. doi:10.1016/..mad.2013.11.008.

37. Matafome P, Santos-Silva D, Sena CM, Seica R. Common mechanisms of dysfunctional adipose tissue and obesity-related cancers. Diabetes Metab Res Rev. 2013;29:285-95. doi:10.1002/dmrr.2395.

38. Gong Y, Dou LJ, Liang J. Link between obesity and cancer: role of triglyceride/ free fatty acid cycling. Eur Rev Med Pharmacol Sci. 2014;18:2808-20.

39. Balaban $S$, Lee LS, Schreuder M, Hoy AJ. Obesity and cancer progression: is there a role of fatty acid metabolism? Biomed Res Int. 2015;2015:274585. doi:10.1155/2015/274585.

40. Furuhashi M, Hotamisligil GS. Fatty acid-binding proteins: role in metabolic diseases and potential as drug targets. Nat Rev Drug Discov. 2008;7:489-503. doi:10.1038/nrd2589.

41. Hotamisligil GS, Bernlohr DA. Metabolic functions of FABPs-mechanisms and therapeutic implications. Nat Rev Endocrinol. 2015;11:592-605. doi:10. 1038/nrendo.2015.122.

42. Park J, Euhus DM, Scherer PE. Paracrine and endocrine effects of adipose tissue on cancer development and progression. Endocr Rev. 2011;32:550-70. doi:10.1210/er.2010-0030

43. Xiong Y, MCDonald LT, Russell DL, Kelly RR, Wilson KR, Mehrotra M, Soloff AC, LaRue AC. Hematopoietic stem cell-derived adipocytes and fibroblasts in the tumor microenvironment. World J Stem Cells. 2015;7:253-65. doi:10 4252/wjsc.v7.i2.253.

44. Wang C, Gao C, Meng K, Qiao H, Wang Y. Human adipocytes stimulate invasion of breast cancer MCF-7 cells by secreting IGFBP-2. PLoS One. 2015: 10:e0119348. doi:10.1371/journal.pone.0119348. 
45. Finley DS, Calvert VS, Inokuchi J, Lau A, Narula N, Petricoin EF, Zaldivar F, Santos R, Tyson DR, Ornstein DK. Periprostatic adipose tissue as a modulator of prostate cancer aggressiveness. J Urol. 2009;182:1621-7. doi:10.1016/j.juro. 2009.06.015.

46. Celis JE, Moreira JM, Cabezon T, Gromov P, Friis E, Rank F, Gromova I. Identification of extracellular and intracellular signaling components of the mammary adipose tissue and its interstitial fluid in high risk breast cancer patients: toward dissecting the molecular circuitry of epithelial-adipocyte stromal cell interactions. Mol Cell Proteomics. 2005;4:492-522. doi:10.1074/ mcp.M500030-MCP200.

47. Pistone Creydt V, Fletcher SJ, Giudice J, Bruzzone A, Chasseing NA, Gonzalez EG, Sacca PA, Calvo JC. Human adipose tissue from normal and tumoral breast regulates the behavior of mammary epithelial cells. Clin Transl Oncol. 2013;15:124-31. doi:10.1007/s12094-012-0896-x.

48. Puisieux A, Brabletz T, Caramel J. Oncogenic roles of EMT-inducing transcription factors. Nat Cell Biol. 2014;16:488-94. doi:10.1038/ncb2976.

49. Lamouille S, Subramanyam D, Blelloch R, Derynck R. Regulation of epithelialmesenchymal and mesenchymal-epithelial transitions by microRNAs. Curr Opin Cell Biol. 2013;25:200-7. https://doi.org/10.1016/j.ceb.2013.01.008.

50. Schulze A, Harris AL. How cancer metabolism is tuned for proliferation and vulnerable to disruption. Nature. 2012;491:364-73. doi:10.1038/nature11706.

51. Currie E, Schulze A, Zechner R, Walther TC, Farese RVJ. Cellular fatty acid metabolism and cancer. Cell Metab. 2013;18:153-61. doi:10.1016/j.cmet. 2013.05.017

52. Ros S, Santos CR, Moco S, Baenke F, Kelly G, Howell M, Zamboni N, Schulze A. Functional metabolic screen identifies 6-phosphofructo-2-kinase/fructose2,6-biphosphatase 4 as an important regulator of prostate cancer cell survival. Cancer Discov. 2012;2:328-43. doi:10.1158/2159-8290.CD-11-0234.

53. Daniels VW, Smans K, Royaux I, Chypre M, Swinnen JV, Zaidi N. Cancer cells differentially activate and thrive on de novo lipid synthesis pathways in a low-lipid environment. PLoS One. 2014;9:e106913. doi:10.1371/journal.pone. 0106913.

54. Nieman KM, Romero IL, Van Houten B, Lengyel E. Adipose tissue and adipocytes support tumorigenesis and metastasis. Biochim Biophys Acta. 2013;1831:1533-41. https://doi.org/10.1016/j.bbalip.2013.02.010.

55. Hu J, Liu Z, Wang X. Does TP53 mutation promote ovarian cancer metastasis to omentum by regulating lipid metabolism? Med Hypotheses. 2013;81:515-20. https://doi.org/10.1016/j.mehy.2013.06.009.

56. Nath $A$, Li I, Roberts $L R$, Chan C. Elevated free fatty acid uptake via CD36 promotes epithelial-mesenchymal transition in hepatocellular carcinoma. Sci Rep. 2015;5:14752. https://doi.org/10.1038/srep14752.

57. Thumser AE, Moore JB, Plant NJ. Fatty acid binding proteins: tissue-specific functions in health and disease. Curr Opin Clin Nutr Metab Care. 2014;17: 124-9. doi:10.1097/MCO.0000000000000031.

58. Cao H, Sekiya M, Ertunc ME, Burak MF, Mayers JR, White A, Inouye K, Rickey LM, Ercal BC, Furuhashi M, Tuncman G, Hotamisligil GS. Adipocyte lipid chaperone AP2 is a secreted adipokine regulating hepatic glucose production. Cell Metab. 2013;17:768-78. doi:10.1016/..cmet.2013.04.012.

59. Uehara $H$, Takahashi T, Oha M, Ogawa H, Izumi K. Exogenous fatty acid binding protein 4 promotes human prostate cancer cell progression. Int J Cancer. 2014;135:2558-68. doi:10.1002/ijc.28903.

\section{Submit your next manuscript to BioMed Central and we will help you at every step:}

- We accept pre-submission inquiries

- Our selector tool helps you to find the most relevant journal

- We provide round the clock customer support

- Convenient online submission

- Thorough peer review

- Inclusion in PubMed and all major indexing services

- Maximum visibility for your research

Submit your manuscript at www.biomedcentral.com/submit
Biomed Central 